\title{
construcción de un pavimento rígido con máquina de encofrado deslizante en la autopista París-Lyón
}

ALVARO GARCIA MESEGUER, ingeniero de caminos

$514-51$

\section{sînopsis}

Se describe la ejecución de un pavimento de hormigón en masa con la máquina de encofrado deslizante Gunter-Zimmerman, de fabricación norteamericana. Esta máquina, que se guía automáticamente por medio de contactos electrónicos, realiza, sin solución de continuidad, las siguientes operaciones: reparte el hormigón a todo ancho $(7,50 \mathrm{~m})$, lo vibra, le da forma y espesor definitivos en su encofrado deslizante, ejecuta una ranura longitudinal que actúa de junta, rellena esa ranura con una cinta de plástico, introduce unas armaduras de cosido de la junta a medio espesor de la losa e iguala la superficie final. Después de referirse al acabado superficial, al curado, a la ejecución por aserrado de juntas transversales y a diversos ensayos y comprobaciones, analiza el autor las posibilidades y limitaciones de este procedimiento, llegando a las conclusiones que aparecen al final del texto.

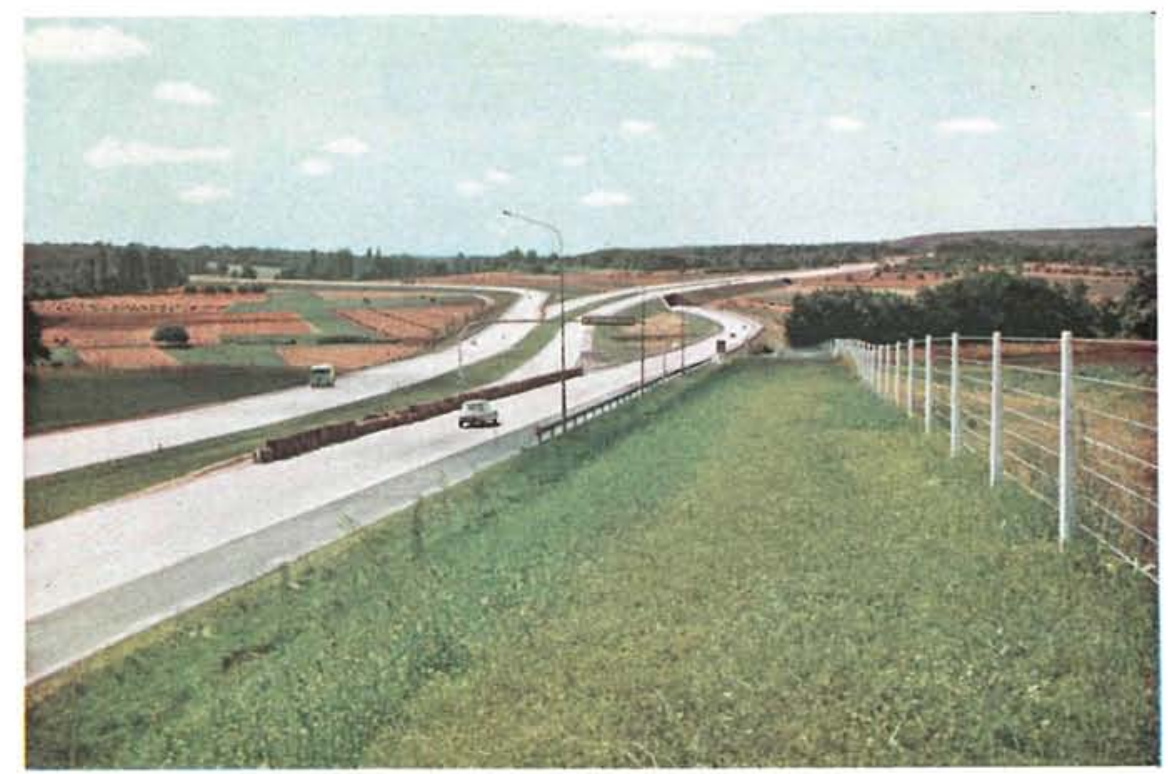

He tenido ocasión de visitar este verano las obras de construcción de la Autoroute du Sud, de París a Lyón, que se realizan ahora en el tramo Corbeil-Egréville, próximo a Fontainebleau. Esta autopista presenta el interés de que en ella se utiliza, para la ejecución del pavimento de hormigón, una máquina de encofrado deslizante; caso éste único en Europa, según mis noticias. Por eso me ha parecido oportuno redactar estas notas, sin pretensión de artículo documentado. con el fin de ofrecer algunas fotografias informativas sobre esta modalidad de construcción. Al paso, incluiré los comentarios y opiniones personales que me ha sugerido mi breve experiencia en esta obra.

\section{Descripreión genemend}

La figura I muestra la semisección transversal tipo de la autopista. Esta consta de dos circulaciones, separadas por una mediana de $10 \mathrm{~m}$ de anchura. Cada circulación comprende: $7,50 \mathrm{~m}$ de pavimento de hormigón en masa, de $25 \mathrm{~cm}$ de espesor, cimentado sobre una capa de $15 \mathrm{~cm}$ de grava-cemento; un arcén derecho de $2,75 \mathrm{~m}$, realizado en grava-cemento de $15 \mathrm{~cm}$ de espesor, con capa de rodadura bituminosa; y un arcén izquierdo de $0,75 \mathrm{~m}$, de suelo estabilizado con tratamiento superficial bituminoso.

Para una exposición ordenada de la obra, podemos distinguir los siguientes apartados:

- estación de grava-cemento,

— estación de hormigonado y

- puesta en obra y acabado de la grava-cemento, - ejecución del pavimento.

De estos cuatro apartados, es el último el que posee mayor interés por su novedad, y el que merece comentarios más extensos. De los otros haré una somera descripción. 


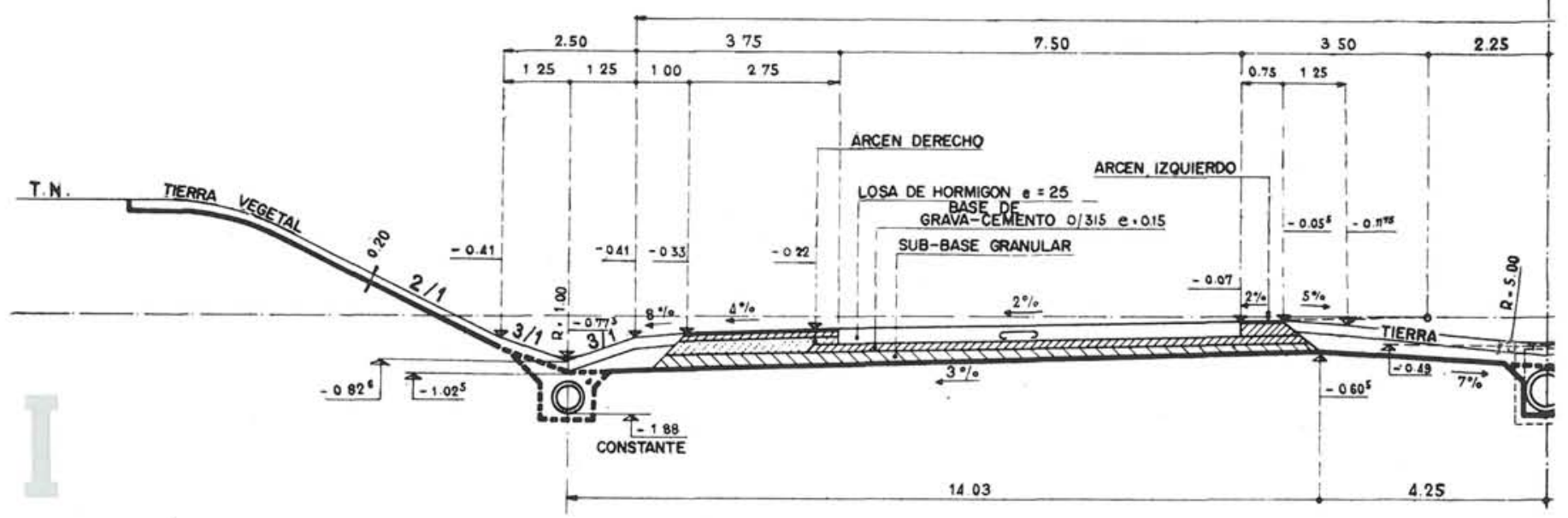

\section{Estackión elle grouwa-cemento}

El árido se obtiene por machaqueo de gravas de aluvión del Sena, hasta un tamaño máximo de $30 \mathrm{~mm}$. A este árido medio se añade arena en proporciones variables para conseguir una curva granulométrica preestablecida, en la que se admiten muy pequeñas tolerancias. El material resultante es un suelo granular de excelentes características, al que se adiciona un 5 por 100 de cemento para formar la grava-cemento. Yo no sé si este nombre de grava-cemento está correctamente empleado aquí, o si debe reservarse para designar el material obtenido mezclando únicamente grava gruesa con cemento en pequeñas cantidades; aunque, en realidad, este último material es un hormigón sin finos. Los franceses llaman grava-cemento al primero, $\mathrm{y}$ no suelo-cemento, porque lo que manejan es un árido preparado $y$ no un suelo. Pero la verdad es que, con una granulometría tan pequeña, su aspecto es, exactamente, el de un suelo-cemento, y yo no creo que deba hacerse ninguna distinción en el nombre. No obstante, conservaré en este artículo la nomenclatura francesa.

La estación de grava-cemento está organizada según el esquema de la figura II y funciona de un modo totalmente automático. La fotografía 1 da una idea de la sencillez de la instalación.



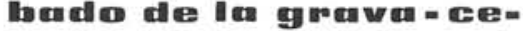 mento}

El transporte se realiza en camiones, y la puesta en obra y compactación se lleva a cabo mediante niveladoras de hoja móvil, rodillos de neumáticos y compactadoras vibratorias. Las fotografías $2 \begin{array}{lll}\mathbf{y} & 3\end{array}$ corresponden a esta fase.

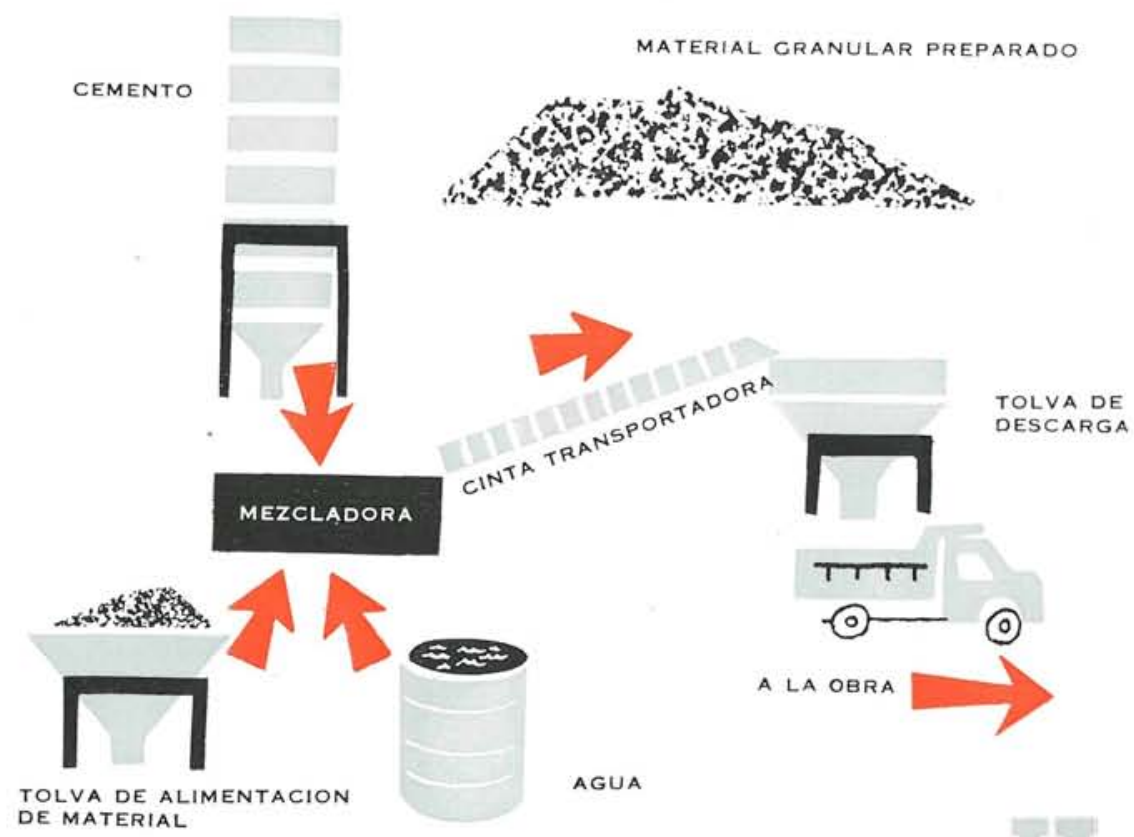

\section{Cstación ghrava-cemento}


El Pliego de Condiciones prescribe una compactación 100 por 100 Proctor modificado. Aun cuando no se exigen ensayos de resistencia, éstos se realizan periódicamente y los resultados oscilan, a compresión, entre 25 y 50 kilogramos $/ \mathrm{cm}^{2}$ a los 7 días y entre 90 y $100 \mathrm{~kg} / \mathrm{cm}^{2}$ a los 28 días. La comprobación del contenido en cemento se lleva a cabo con un calorímetro, midiendo la elevación de temperatura que se produce al tratar una muestra con ácido clorhídrico. A uno se le ocurre preguntar qué sucede cuando el árido es calizo. La respuesta es que, en ese caso, se realizan las oportunas correcciones. No obstante, surgen ciertas dificultades y la precisión de la medida no supera, entonces, un \pm 10 por 100 referido al contenido en cemento.

La dosificación real de cemento es, como he dicho, de un 5 por 100 , aun cuando el Pliego de Condiciones no exige más que un $3 \pm 0,2$ por 100 . Se decidió este aumento al comprobar que, con una dosificación más baja, la máquina de encofrado deslizante «patinaban sobre la grava-cemento. Como es natural, la dosificación alta provoca un mayor agrietamiento por retracción, lo cual no parece tener importancia.

El acabado se realiza con una "form-grader» (fotografía 4), que termina dos franjas laterales, y una "fine-gradern, que termina la parte central apoyándose en los laterales ya acabados. Se admite una tolerancia máxima de nivelación de $\pm 1 \mathrm{~cm}$. Es interesante reseñar que la tarea de acabado estaba a cargo de una empresa diferente de la que ponía en obra la grava-cemento, lo cual dificultaba la armonización de los ritmos de trabajo y era origen de pequeños roces en obra.

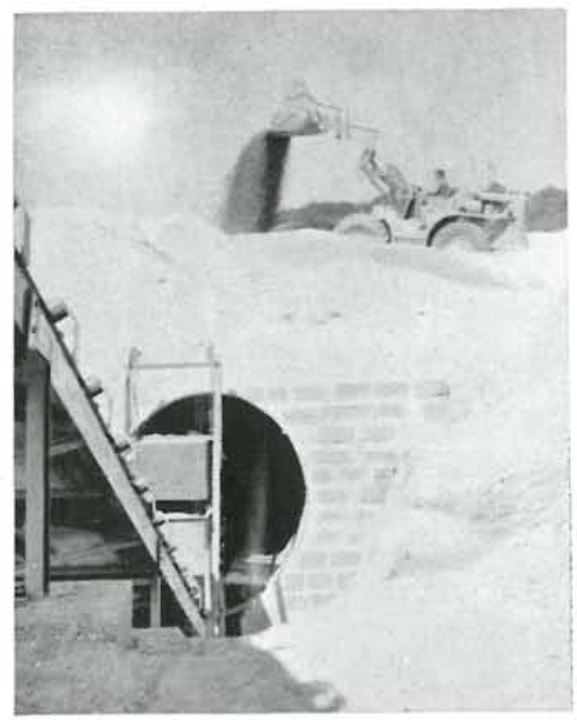

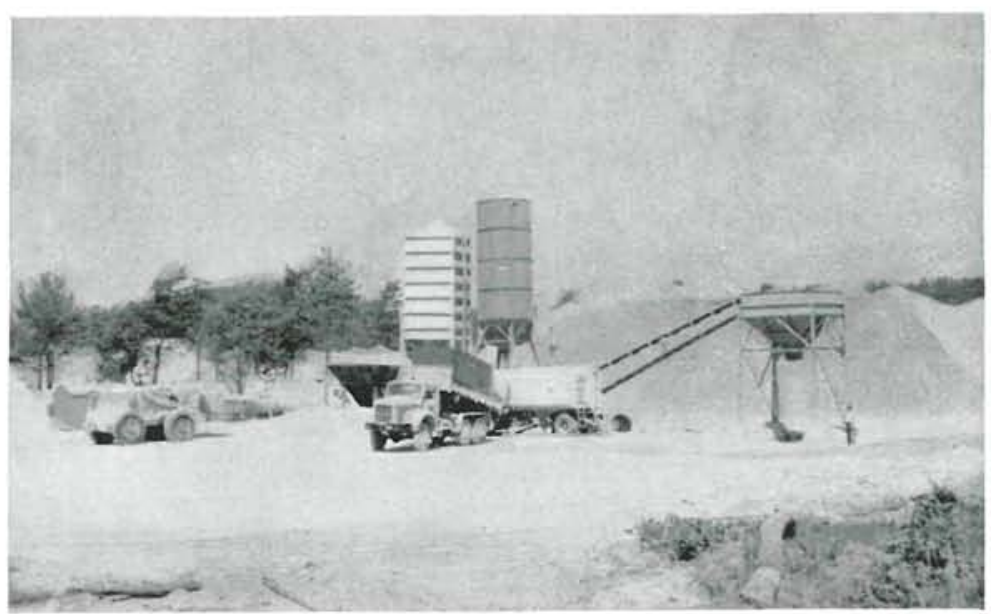
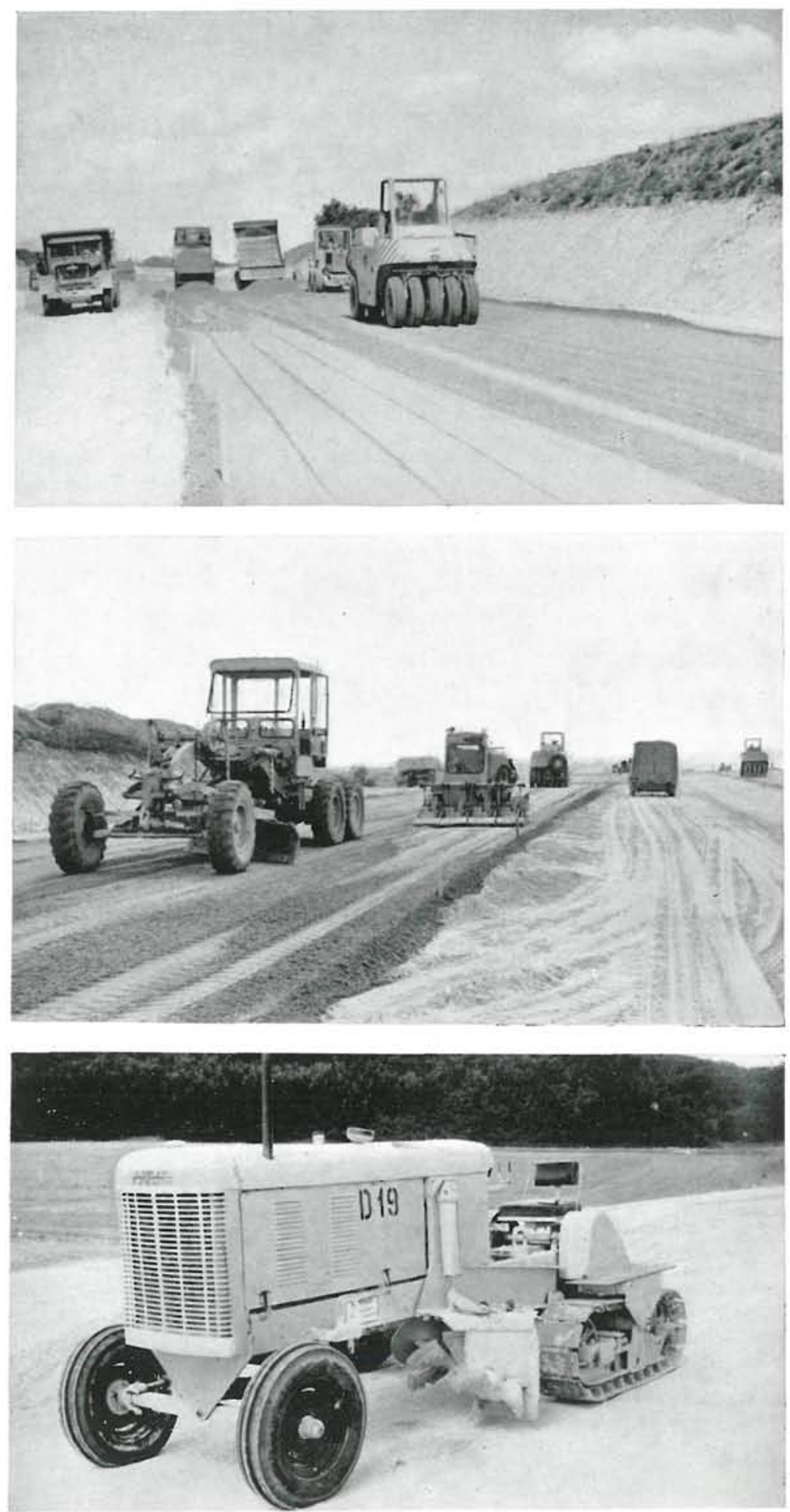

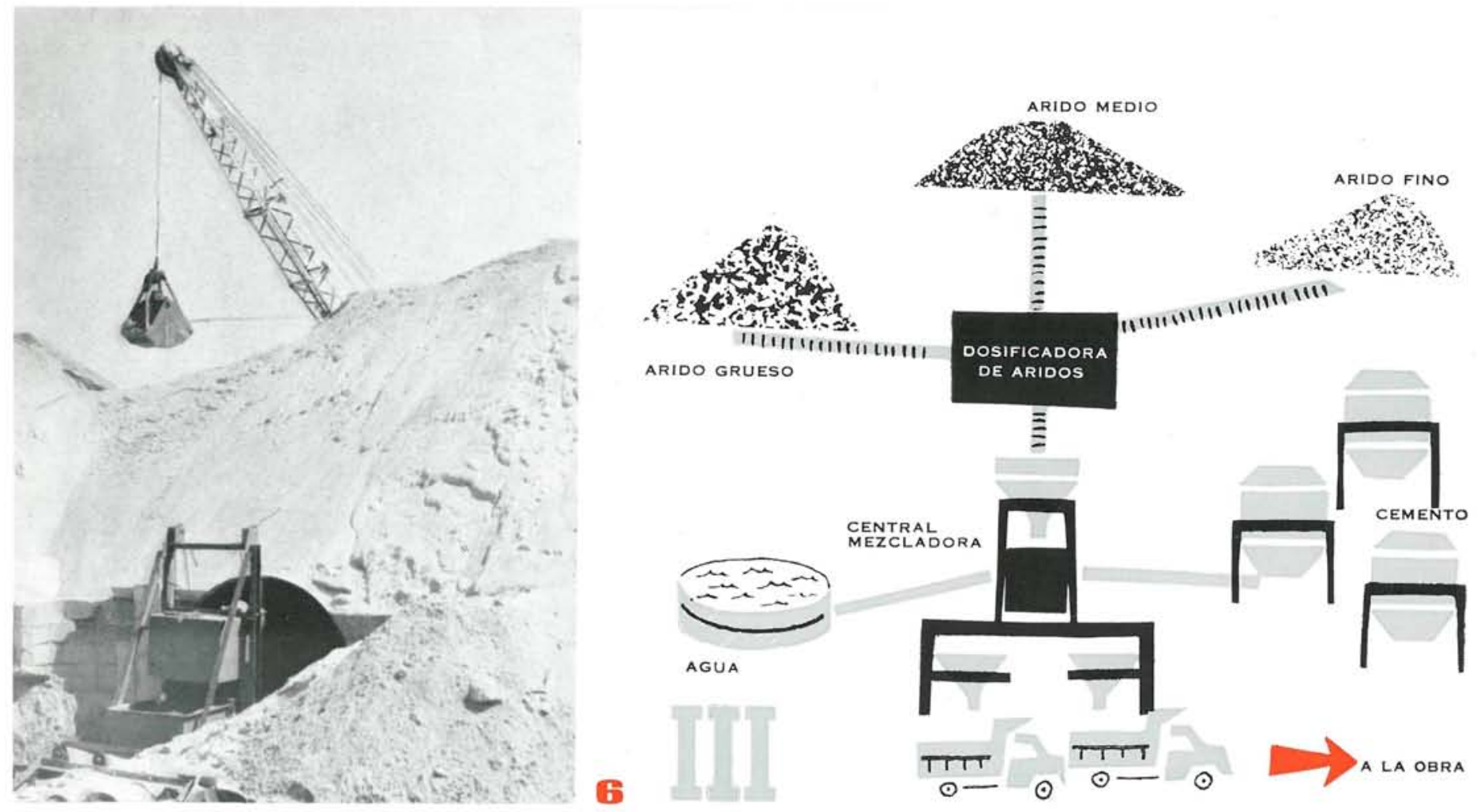

\section{Estración de lhormignomado}

Está colocada hacia la mitad del tramo en construcción (unos $10 \mathrm{~km}$ de longitud) y su disposición, muy racional, es la del esquema de la figura 3. Los áridos se apilan en grandes montones al aire libre, debajo de cada uno de los cuales se coloca, en túnel, una tolva de recogida y una cinta transportadora. La alimentación resulta, así, muy simple: se realiza mediante una pala cargadora cuya misión se reduce a tomar áridos de los bordes del montón y descargarlos en el centro del mismo, en la parte más alta de la pila, sobre la tolva. Se hace de este modo con el árido grueso $(20-40 \mathrm{~mm}$ ) y con el medio $(5-20 \mathrm{~mm})$, como muestra la fotografía 5. En el caso de la arena, como la pala cargadora no podria subir por la pila, se sustituye por una pluma con cuchara (fotografía 6). La fotografía 7 muestra el embudo natural de descarga que se forma en la vertical de la tolva.

El suministro de agua se asegura mediante una balsa circular de lona impermeabilizada, procedimiento cómodo y barato. La fotografía 8 muestra esa balsa en primer término; en segundo término aparece la central dosificadora, a la que acceden las tres cintas transportadoras de áridos, y de la que parte una cuarta cinta, hacia la central de amasado.

La central amasadora posee dos tambores de eje horizontal, con $2 \mathrm{~m}^{3}$ de capacidad cada uno, que trabajan decalados para conseguir el máximo rendimiento. En la fotografía 9, el tambor izquierdo está amasando (hay un camión en espera) y el derecho acaba de descargar. Se asezura así un suministro de hormigón de $120 \mathrm{~m}^{3} / \mathrm{hora}$

El asegurar un funcionamiento impecable de la central de hormigonado es imprescindible cuando se trabaja con una máquina de encofrado deslizante, pues los trastornos que causan las paradas son mucho más perjudiciales en este caso, como más adelante veremos,
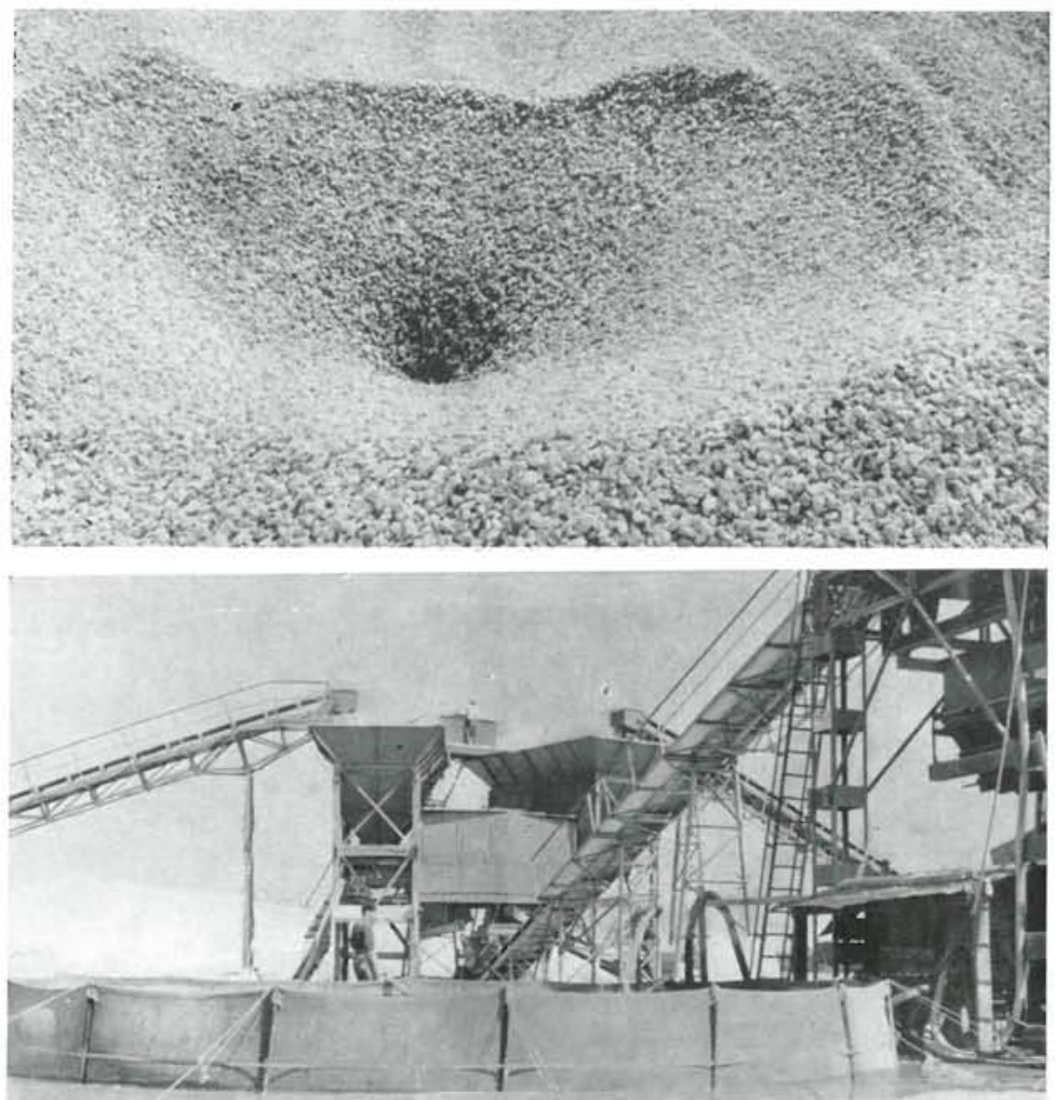
que cuando se utilizan otros procedimientos de ejecución. Además, la regularidad y constancia en la dosificación y la bondad del amasado son factores cuya descorrección repercute inmediatamente en la facilidad de trabajo y en la calidad del acabado que proporciona la máquina de ejecución. Por todo ello, puede decirse que al menos un 75 por 100 de las dificultades que pueden presentarse al trabajar con este tipo de máquina, tienen su origen en la central de hormigonado.

Una de las causas de posible trastorno radica en la humedad de los áridos, que no puede dejar de tenerse en cuenta para la dosificación. En la obra a que me refiero (en la que, por supuesto, la dosificación se realiza en peso y no en volumen), los áridos llegaban a retener hasta 60 litros por metro cúbico en dias no muy lluviosos y era, a menudo, difícil de conseguir una constancia en el contenido de agua de los amasijos, a pesar de la cuidadosa vigilancia existente.

\section{Ejecución del pavimento}

La capa de grava-cemento terminada se sella con un ligero riego de emulsión bituminosa y una delgada capa de arena fina, para impedir la evaporación del agua. Con esto queda lista la superficie para el paso de la máquina de encofrado deslizante.

El aspecto de dicha superficie se muestra en la fotografía 10, que está tomada desde el punto mismo en que se encuentra la máquina. La disposición no puede ser más simple: no existen encofrados, ni juntas preparadas, ni papel de base, ni armaduras... La única instalación que requiere la máquina, por delante de ella, es un par de alambres-guias, uno a cada lado de la explanación, sostenidos por una fila de piquetes metálicos. Tales piquetes se colocan, cada $7,50 \mathrm{~m}$, junto a estaquillas cuidadosamente replanteadas (fotografía 11) y se reglan en altura convenientemente de manera que el alambre resulte horizontal y bien tenso.

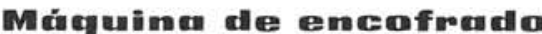 destizerate}

La fotografía 12 muestra la máquina de encofrado deslizante, vista de frente. Es un prototipo creado en California, por la casa GUNTER-ZIMMERMAN, y responde al esquema de la figura 4 . Va montada sobre orugas y ejecuta todo el ancho $(7,50 \mathrm{~m})$ del pavimento, en hormigón en masa, con una junta longitudinal central $(3,75+3,75 \mathrm{~m})$ cosida cada $50 \mathrm{~cm}$ con anclajes $\varnothing 8$ de acero corrugado.

La velocidad de avance es regulable (capaz de alcanzar los $5 \mathrm{~m} / \mathrm{min}$ ), pero puede darse como valor medio el de $1,50 \mathrm{~m} / \mathrm{min}$. En la obra se conseguia un rendimiento diario variable entre 400 y $600 \mathrm{~m}$.1, llegándose a un máximo de 700 metros.

La alimentación de la máquina se efectúa por delante, mediante dos camiones que reculan contra ella, uno a cada lado, hasta tropezar con los topes móviles correspondientes; después de lo cual, elevan la caja y descargan por la parte trasera. Los topes móviles mencionados tienen una carrera suficiente para absorber la longitud de avance de la máquina en el transcurso de la maniobra, con lo cual no es necesario parar y todo se realiza de un modo continuo.
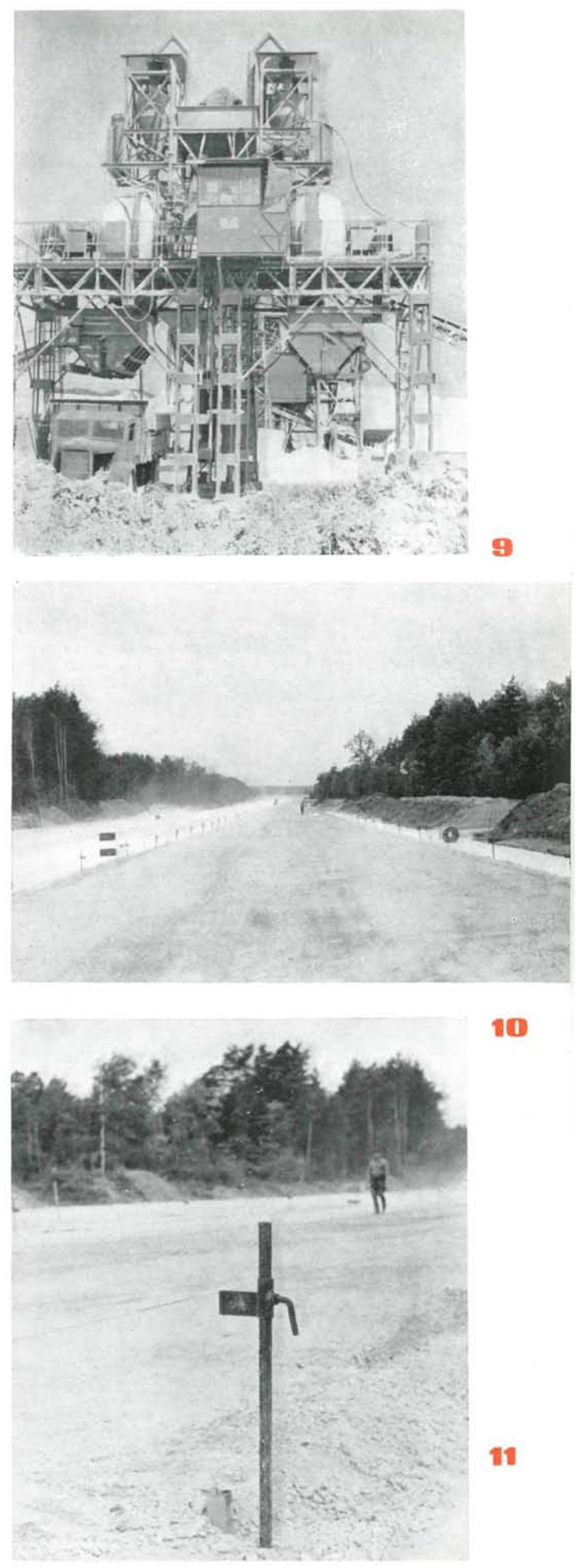


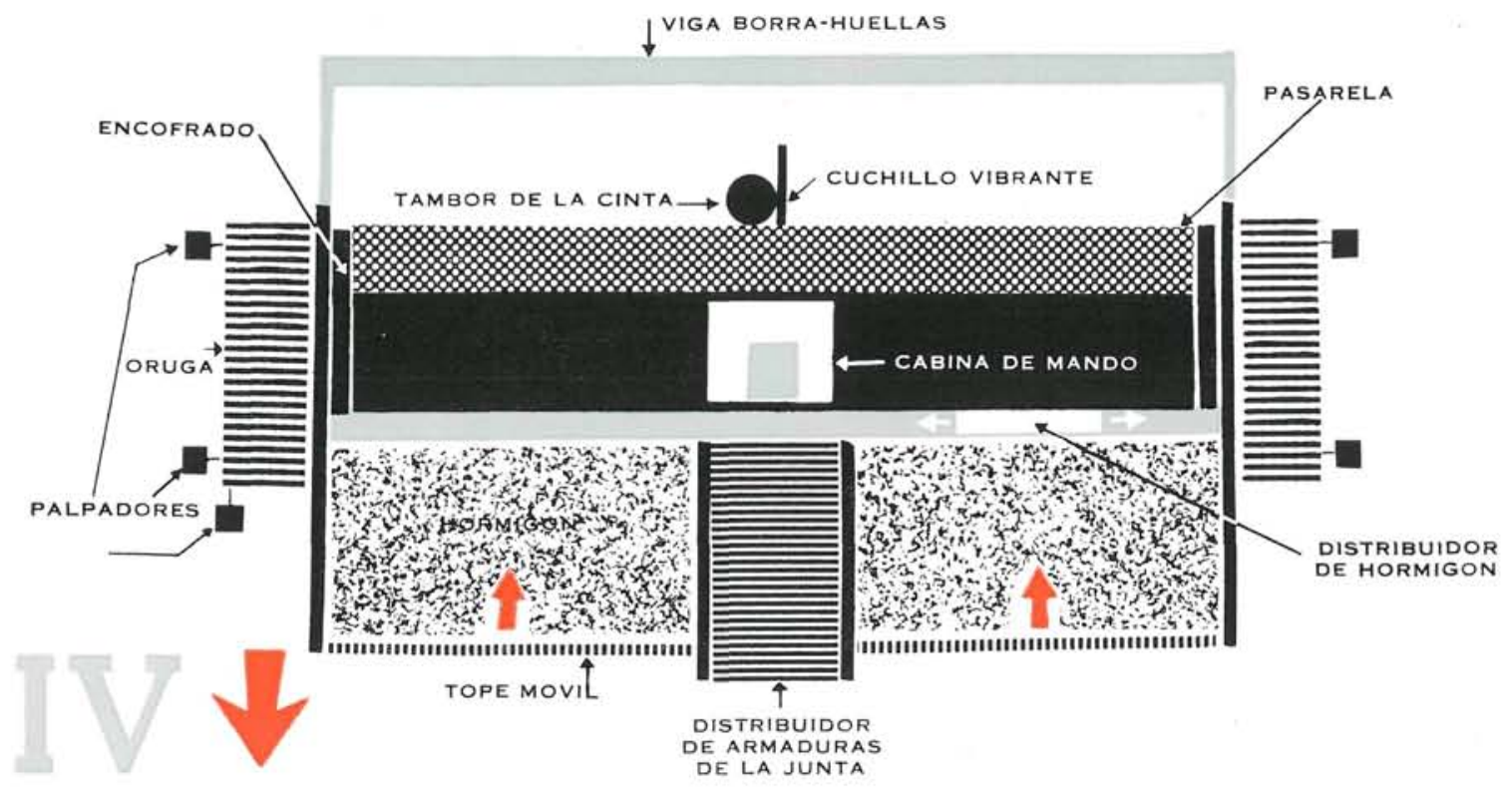

La fotografía 13, tomada desde lo alto de la cabina de mando, muestra el distribuidor de armaduras de la junta longitudinal (una cadena sin fin en la que van colocados los anclajes), colocado en la parte central delantera de la máquina. Este distribuidor va disponiendo un redondo cada $50 \mathrm{~cm}$, en la mitad del espesor de la losa. A cada lado del mismo se observan los compartimientos de descarga del hormigón y los topes móviles correspondientes.

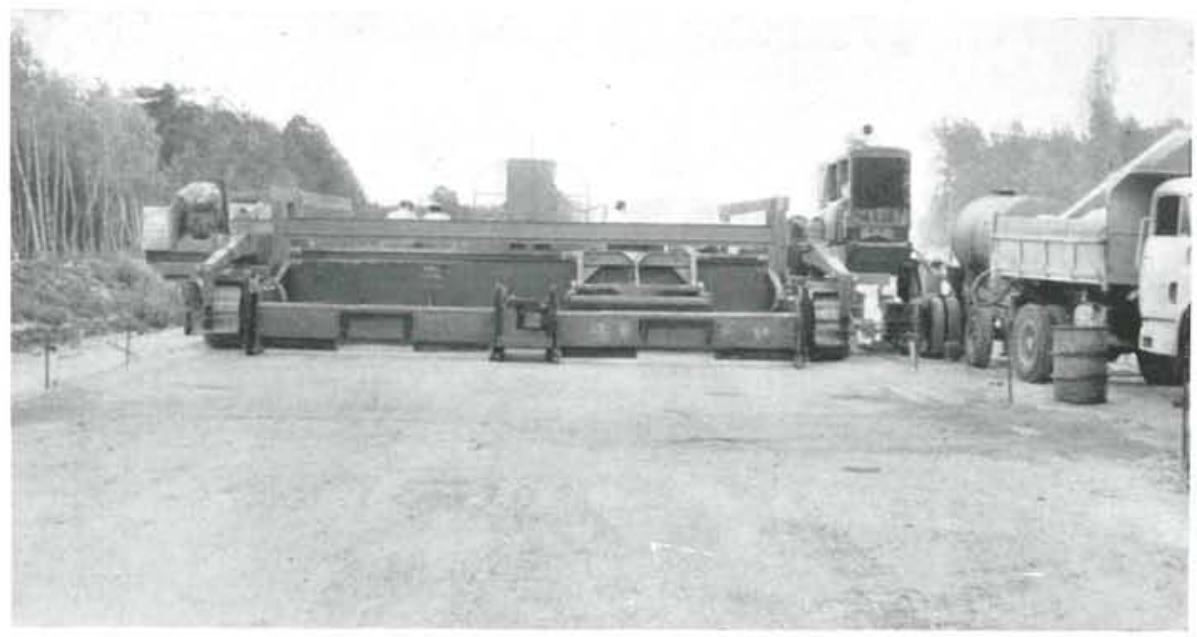

Una vez vertido el hormigón, éste es repartido en todo el frente de la máquina, ayudando a ese reparto el carretón móvil que se aprecia en la fotografía 12, a media altura, a la derecha. Luego se vibra la masa por medio de una batería de vibradores de aguja. Por último, pasan los encofrados deslizantes, que son dos perfiles metálicos, dando la forma y espesor definitivos a la losa de hormigón.

El guiado de la máquina se realiza automáticamente mediante cinco palpadores de contactos electrónicos, que siguen los alambres-guia mencionados anteriormente. En la parte delantera derecha de la máquina hay un palpador horizontal que guía en altura y otro vertical que guia en dirección (fotografía 14). En la parte delantera izquierda y en la parte trasera, sólo son necesarios los palpadores horizontales, para asegurar la constancia del espesor.

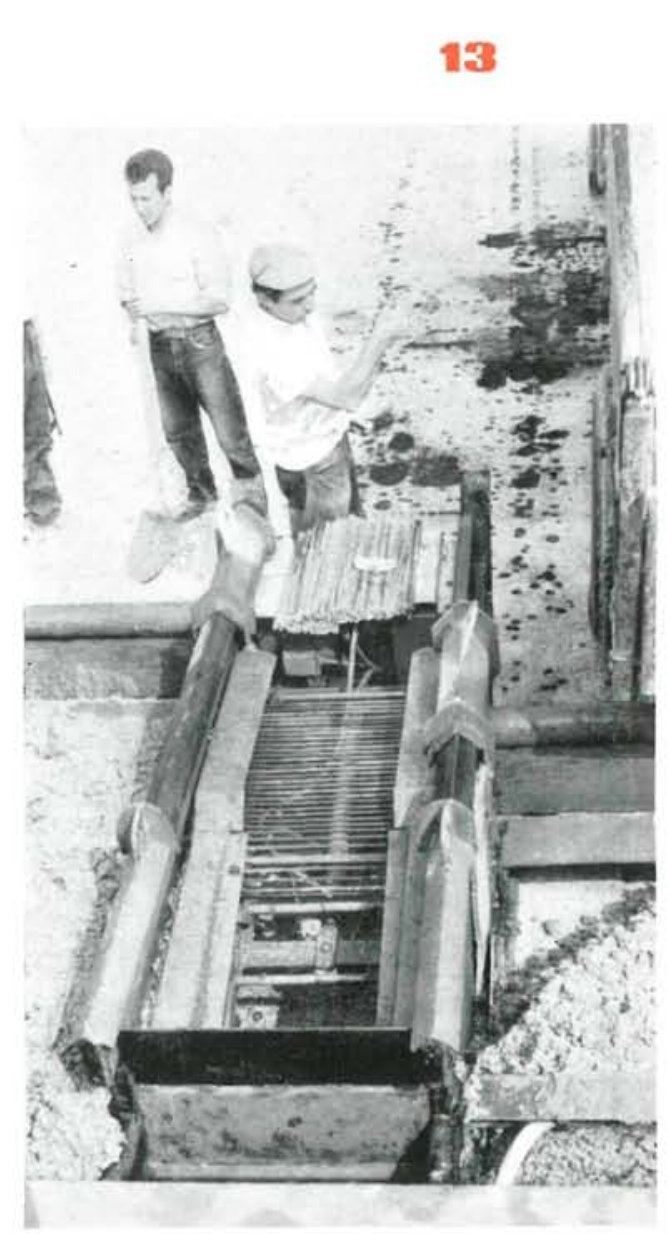


Todos los palpadores están articulados, para poder salvar, girando sobre su eje, el paso por los piquetes metálicos que sostienen el alambre.

La fotografía 15 muestra la parte trasera de la máquina en un momento de comienzo del trabajo de un día. Se aprecia en el lateral el perfil metálico que actúa de encofrado, que acaba de dar forma a un trozo de losa cuyo color contrasta con el del hormigón ya endurecido del día anterior. Suspendida de dos vigas en voladizo y atravesada a todo lo ancho del pavimento, aparece la viga borra-huellas cuya misión veremos inmediatamente.

La fotografía 16 ofrece con más detalle la parte central trasera de la Gunter-Zimmerman El cuchillo vibrante se hunde en el hormigón recién ejecutado y realiza un surco de unos $5 \mathrm{~cm}$ de profundidad, que constituye la junta longitudinal. Al mismo tiempo, una cinta de plástico de igual dimensión, alojada en el tambor que aparece en la fotografía, se enhebra por el cuchillo metálico como el hilo en la aguja (fotografía 17), y va guarneciendo el surco antedicho, con lo que la junta se abre y se rellena a la vez Inmediatamente detrás del cuchillo, la viga borra-huellas pasa presionando ligeramente la zona central de la losa, y borra así completamente el surco realizado, dejando la superficie perfectamente lisa, sin solución de continuidad en la junta. Por otro lado, las armaduras que fue colocando el distribuidor delantero, a medio espesor de la losa, resultan centradas con la junta, cosiéndola cada $50 \mathrm{~cm}$. El resultado es una junta longitudinal ciega provista de anclajes, construida en dos etapas que se suceden con pocos instantes de intervalo.

Un detalle del encofrado deslizante se ve en la fotografía 18, donde también aparece el palpador horizontal trasero derecha. Corresponde, igualmente, esta fotografía al comienzo del trabajo de un día.

\section{Acabeado superfician}

La máquina de encofrado deslizante deja la superficie de la losa perfectamente lisa. Para quitar la lechada superficial, se pasa longitudinalmente un tubo de aluminio a todo lo ancho, inclinado $45^{\circ}$ con respecto al eje del firme y arrastrado por una cuerda de cada lado (fotografía 19). Es importante que el tubo deslice y no ruede. Se dan cuatro pasadas, girando cada vez $90^{\circ}$ la inclinación del tubo.

Detrás del tubo se hacen pasar dos lonas húmedas montadas sobre ruedas, cuyo arrastre proporciona una cierta textura superficial, que será la definitiva del pavimento. En la fotografía 19 se ven esas lonas en último término.

La calidad de rodadura que se obtiene con ese acabado es aceptable, pero no llega a proporcionar los excelentes resultados que se consiguen utilizando terminadoras longitudinales.
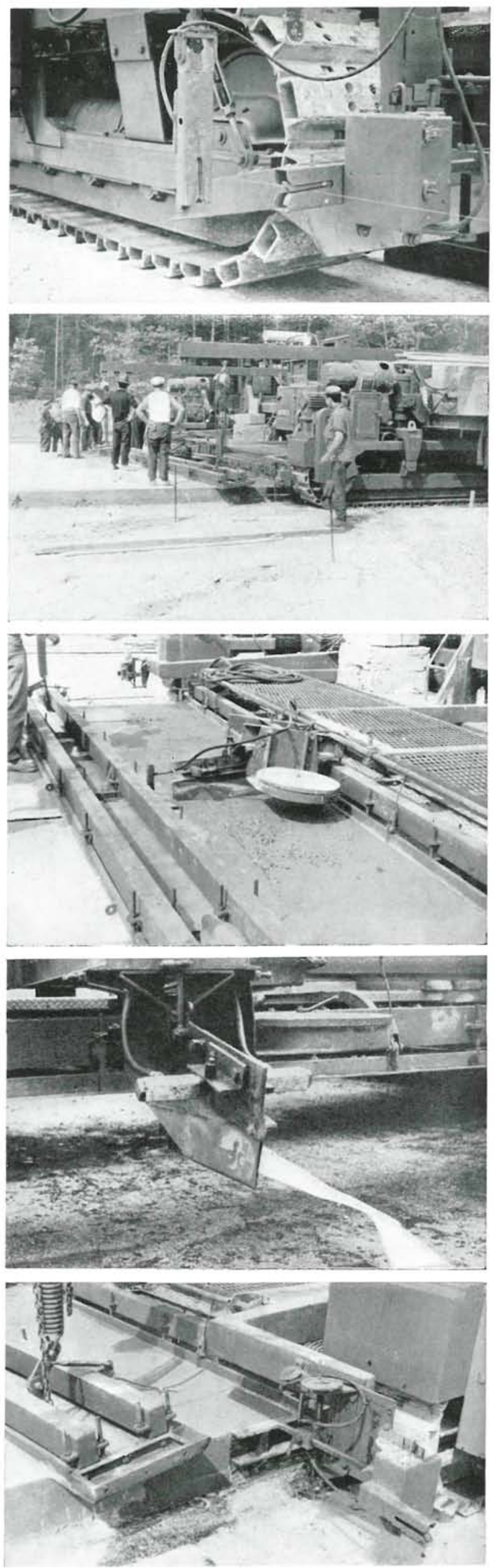

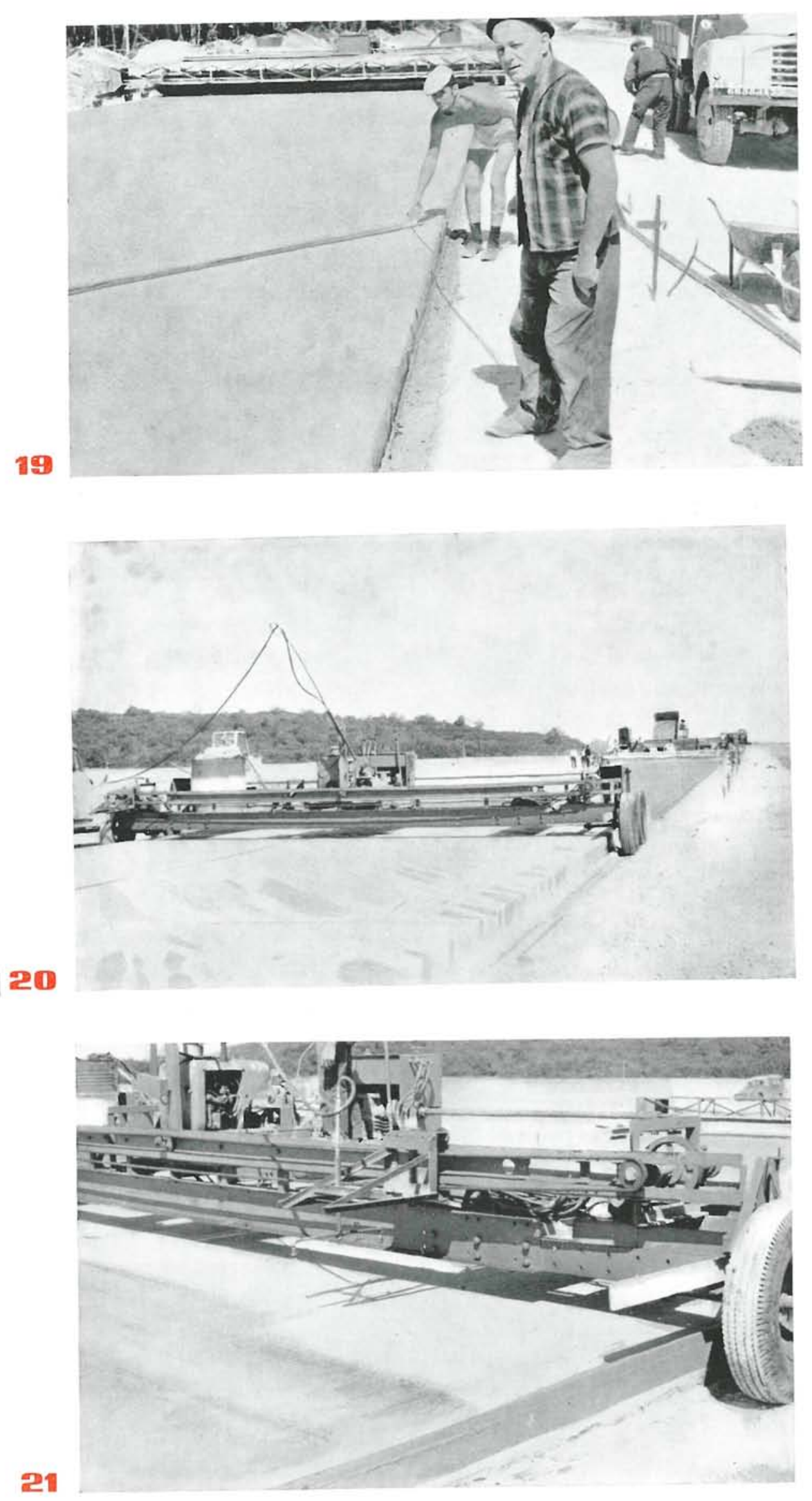

\section{Eum ara}

Detrás de las lonas pasa la máquina repartidora del producto de curado. Como muestra la fotografía 20, ésta consiste en una lanza central unida por un conducto flexible a una corredera que va y viene a todo lo ancho del pavimento, provista de dos aspersores para pulverizar el producto. La fotografía 21 permite apreciar cómo se realiza el reparto. En este caso, el producto estaba pigmentado de verde y se había obturado adrede uno de los dos aspersores para conseguir una mayor presión en la boquilla del otro. LoS laterales de la losa se impregnan posteriormente a mano. Puede observarse en esta última fotografía que el reparto no es todo lo uniforme que sería deseable, sino que, por el contrario, se forman surcos de diferente intensidad. La cantidad correcta de producto que debe extenderse es, precisamente, la que aparece en las zonas menos intensas, pues las otras zonas presentan un exceso absolutamente inútil. La cantidad óptima es del or.den de 1 litro por cada $5 \mathrm{~m}^{2}$ (véase el comentario al apartado F.3.2 del pliego PR63 del I. E. T. c. c.), y aquí se empleaba, al menos, tres veces más. De las dos posibles causas del derroche (mal reglaje de la máquina o mala disolución del producto) no conseguí enterarme cuál era la verdadera, porque en mis pesquisas me encontré con que cada parte (el representante de la máquina y el representante del producto de curado) culpaba a la parte contraria...

\section{Junters}

\section{Trumsionsentes}

Pasadas unas cuantas horas, cuyo número depende de la temperatura ambiente y otros factores, se procede al aserrado de juntas transversales, cuya separación es de 5 metros. En general, solian serrarse por la tarde las correspondientes al hormigón ejecutado por la mañana, y por la noche las del hormigón de la tarde. Las juntas no se sierran consecutivamente, sino cada dos o cada tres, volviendo luego a ejecutar las intermedias. El cuándo es una cuestión de buen ojo del maquinista correspondiente. 


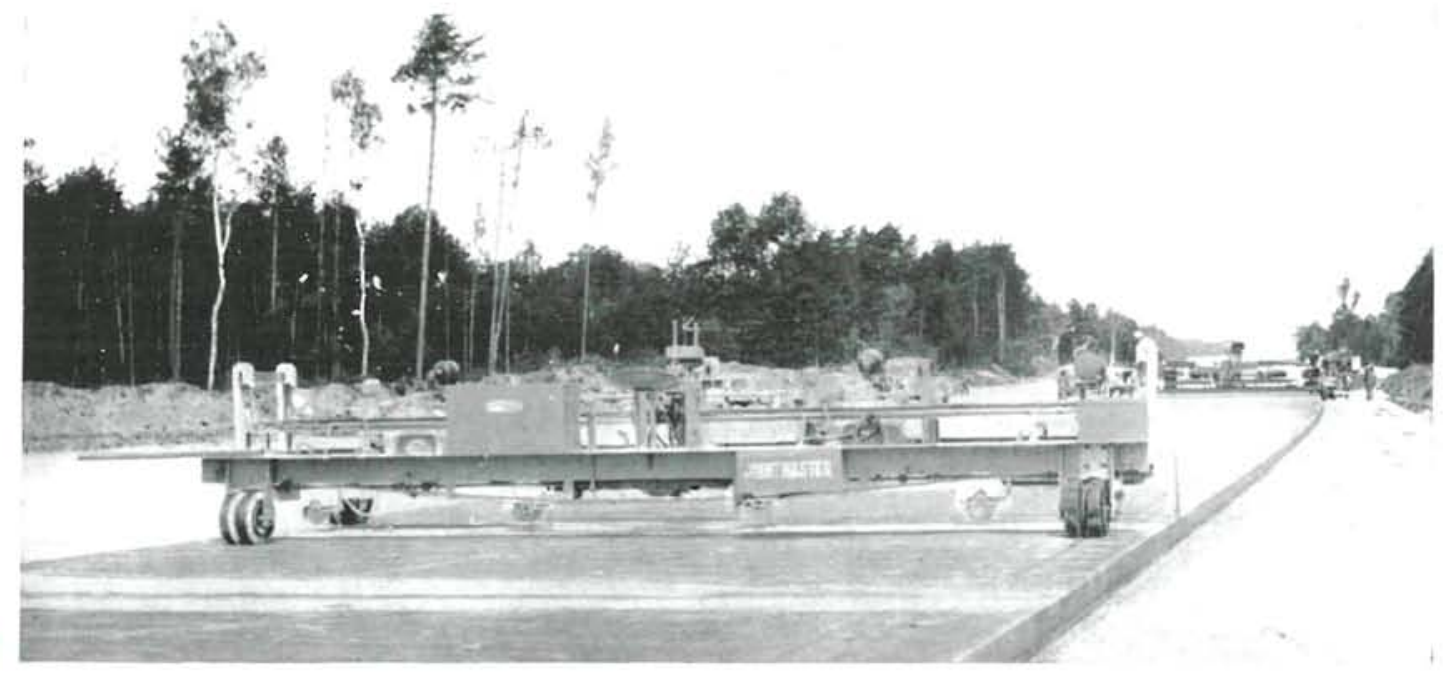

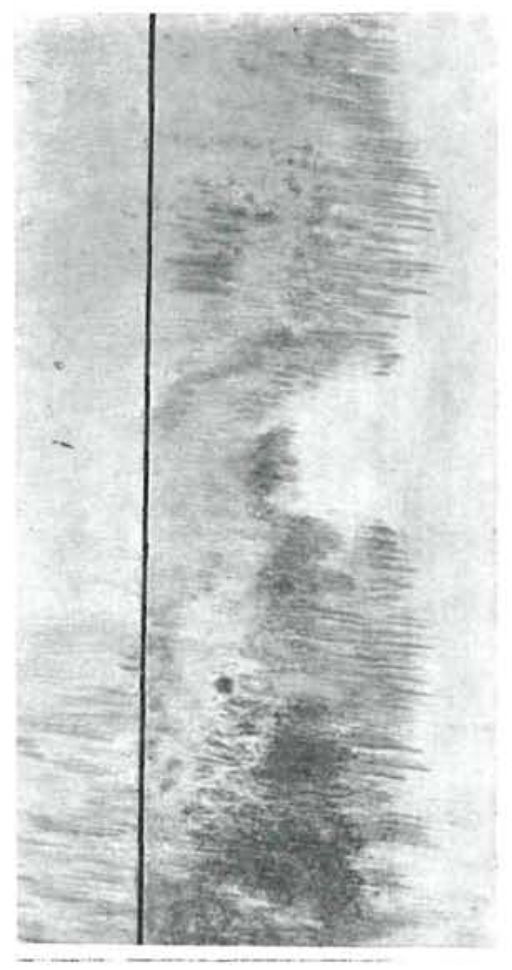
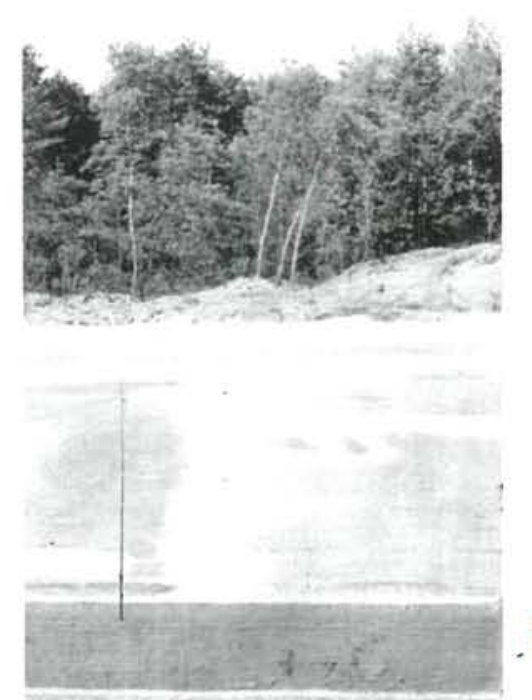

La fotografía 22 muestra la sierra Joint-Master, con cuatro discos de diamante que avanzan mecánicamente y ejecutan un corte perfecto, como puede apreciarse en la fotografía 23. Las juntas no son normales al eje del firme, sino que presentan un ligero esviaje (aproximadamente 1/6), para conseguir una transmisión más gradual de las cargas del tráfico de una losa a la adyacente y una mayor comodidad de rodadura para el usuario. En la fotografía 24 se manifiesta la oblicuidad de la junta, así como la profundidad de aserrado, que es de unos $5 \mathrm{~cm}$. La anchura es de unos pocos milimetros.

Posteriormente, las juntas se obturan provisionalmente con una cuerda, para impedir la entrada de cuerpos extraños. Y mucho más adelante, se rellenan definitivamente con un cuerpo de junta y se sellan con producto bituminoso.

A los 3 ó 4 dias de la ejecución, las juntas comienzan a funcionar: cada cuatro o cinco losas aparecen fisuradas, a causa de la retracción, siguiendo la sección que se debilitó por aserrado.

\section{Enscugos y compromatoiomes}

Sobre el hormigón fresco se realizan los ensayos de asiento y de contenido de aire ocluido (se emplea hormigón con aireante) cada media hora, tomando las muestras de la propia máquina de ejecución; es decir, después de haber sufrido el proceso de transporte (fotografía 25). Se anota la hora, la temperatura al sol y a la sombra y el número de la losa a que corresponden los ensayos.

Se ha comprobado, haciendo determinaciones antes y después, que el vibrado del hormigón provoca una reducción del contenido de aire ocluido variable entre el 0,5 y el 1 por 100 . El valor que suele establecerse para el contenido en aire (véase apartado C.4.3 del pliego PR63 del I. E. T. c. c.) oscila entre el 3 y el 6 por 100 . En esta obra, las determinaciones que yo vi arrojaban valores ligeramente altos, en general.

En cuanto al asiento, que se mide en cono de Abrams, solía resultar muy variable, con valores normales de 6 a $8 \mathrm{~cm}$, siendo asi que el máximo establecido era de $4 \mathrm{~cm}$.

Los resultados de ambos ensayos parecian indicar una falta de perfección en el amasado y, a menudo, un exceso de agua. Tales circunstancias eran, afortunadamente, accidentales y posteriormente se consiguió reglar la central de hormigonado con mayor precisión.

Sobre el hormigón endurecido se efectúan ensayos de regularidad superficial. En sentido longitudinal se pasa una regla rodante de $3 \mathrm{~m}$ de longitud (fotografía 26) por el eje de cada una de las dos vías de circulación. La regla posee una ruedecilla-guía delantera (precedida de un cepillo para limpiar de polvo y piedrecillas el camino) que se acciona, en dirección, desde una de las empuñaduras; una rueda trasera portante, unida a la anterior por una barra rígida, y una rueda palpadora central, que transmite sus movimientos verticales con respecto a la barra, a un cuadrante graduado. Cuando la aguja sobrepasa los $3 \mathrm{~mm}$, en más o en menos, se enciende una luz piloto a uno u otro lado del cuadrante. 

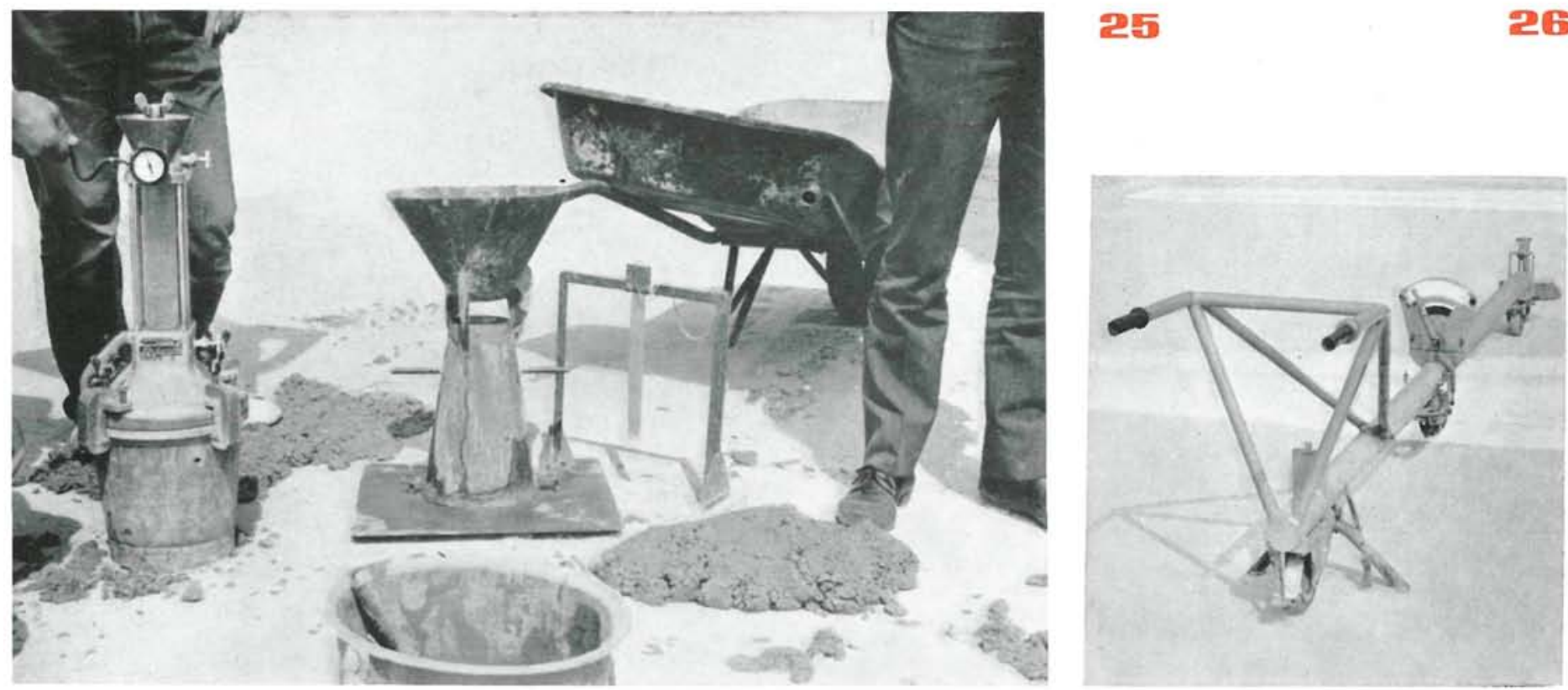

Esta regla es un prototipo creado en Francia, de muy sencillo manejo (un hombre la va empujando, asida por el manillar) y suficientemente precisa.

En sentido transversal, la comprobación se realiza con la regla rodante de la fotografía 27. El principio es el mismo: un par de ruedas portantes a cada lado y cinco ruedecillas palpadoras repartidas a lo ancho, que transmiten sus movimientos, independientemente unas de otras, a una varilla que cierra o no un circuito eléctrico según que la desnivelación relativa a las ruedas portantes supere o no los $5 \mathrm{~mm}$, en más o en menos. Según el signo, se ilumina un piloto rojo o verde, no habiendo en este caso cuadrante graduado.

Junto al operador que empuja la regla por medio de una lanza, va un libretista que anota los defectos en las casillas correspondientes.

La mañana que vi trabajar esta regla, una cierta proporción de losas acusaban defectos de nivelación transversal. La causa parecía radicar en el tubo de aluminio que se pasa para quitar la lechada: si el tubo no está perfectamente limpio y tiene papilla endurecida en su superficie, la nivelación final resulta defectuosa.

De cualquier modo, casi todas las irregularidades pueden corregirse posteriormente por cepillado del pavimento.

\section{Coste}

La máquina de encofrado deslizante trabajaba en esta obra en régimen de alquiler. Dicho alquiler se paga por metro lineal ejecutado y no por dia de empleo. Como es natural, el maquinista es un técnico especializado de la casa Gunter-Zimmerman.

El coste del metro cúbico de hormigón colocado, contados todos los gastos, resulta de unas 1.400 pesetas. Es decir, que, en lo que respecta al pavimento exclusivamente, el coste de 1 kilómetro de autopista es, aproximadamente, de 5 millones de pesetas.

\section{Algumos incomvenientes del procedimiento}

Sin el menor ánimo de crítica hacia la obra que comento (si tuviese que hacer una critica, el balance final sería muy favorable) y sí con el deseo de señalar las limitaciones actuales de la máquina de encofrado deslizante, incluiré ahora algunos de los que, en mi opinión, son inconvenientes del procedimiento. Las ventajas, que son muchas, han quedado más o menos patentes a lo largo de los apartados anteriores. 


\section{Defertos alle gurien al or}

La exactitud del trazado y la constancia de espesor del pavimento están confiadas, como se ha visto, a la precisión de tendido de un alambre. Ya se comprende que, en el tráfago de una obra, un alambre tendido a la altura de las rodillas es un elemento poco visible, cuya integridad está siempre en precario. Es inevitable, por ejemplo, que los obreros tropiecen con él, y, sobre todo, los visitantes, que en una obra así no son escasos. Por mi parte, creo que fueron tres veces las que caí en la trampa. Por mucho cuidado que se ponga en corregir y comprobar a cada momento, no es posible asegurar la perfección del tendido. Y la consecuencia es que el perfil del pavimento pierde, a veces, su regularidad (fotografía 28) o, lo que es más grave, que el espesor puede variar apreciablemente. En la obra a que me refiero, el espesor establecido era de $25 \mathrm{~cm}$ y llegaron a medirse diferencias de $3 \mathrm{~cm}$, en mas o en menos, en algunos puntos.

No obstante lo dicho, el defecto es menos frecuente de lo que pudiera imaginarse y no constituye, por sí solo, un grave inconveniente.

\section{Defectos ale superficie}

Cualquier alteración en la central de hormigonado se acusa inmediatamente, como más arriba queda dicho, en la máquina de ejecución. Aunque la máquina puede regularse a cada momento en velocidad, intensidad de vibración, etc., es siempre difícil conseguir una buena puesta en obra si varian las características del hormigón que la alimenta. La fotografía 29 muestra irregularidades en la superficie recién ejecutada que son debidas a esta causa. Tales irregularidades se corrigen a mano, echando nuevo hormigón y alisando con llana. Pero constituyen, inevitablemente, un punto débil en la vida futura del pavimento.



Como sucede con cualquier proceso continuo, las paradas obligadas por causa de fuerza mayor ocasionan un trastorno no despreciable. Si la máquina se detiene durante poco tiempo, de manera que la masa fresca no llegue a fraguar, el trastorno es mínimo y el único inconveniente radica en la heterogeneidad más o menos apreciable que se introduce en la ejecución al tener que variar el régimen de revoluciones de la máquina. En cambio, si la parada se prolonga unas horas (por corte de energía eléctrica, por avería en la central de hormigonado, etc.), como sucede, claro está, en los finales de jornada, el hormigón endurece y el trastorno es grande. Ello se debe al hecho de que los dos últimos metros de pavimento ejecutados quedan ocultos debajo de la máquina, y, al volver a poner ésta en marcha, la fuerte viga vibrante que juega el papel de encofrado superior, actúa sobre el hormigón endurecido, destrozando cuando menos la parte final del mismo y provocando unas trepidaciones perjudiciales para la propia máquina.
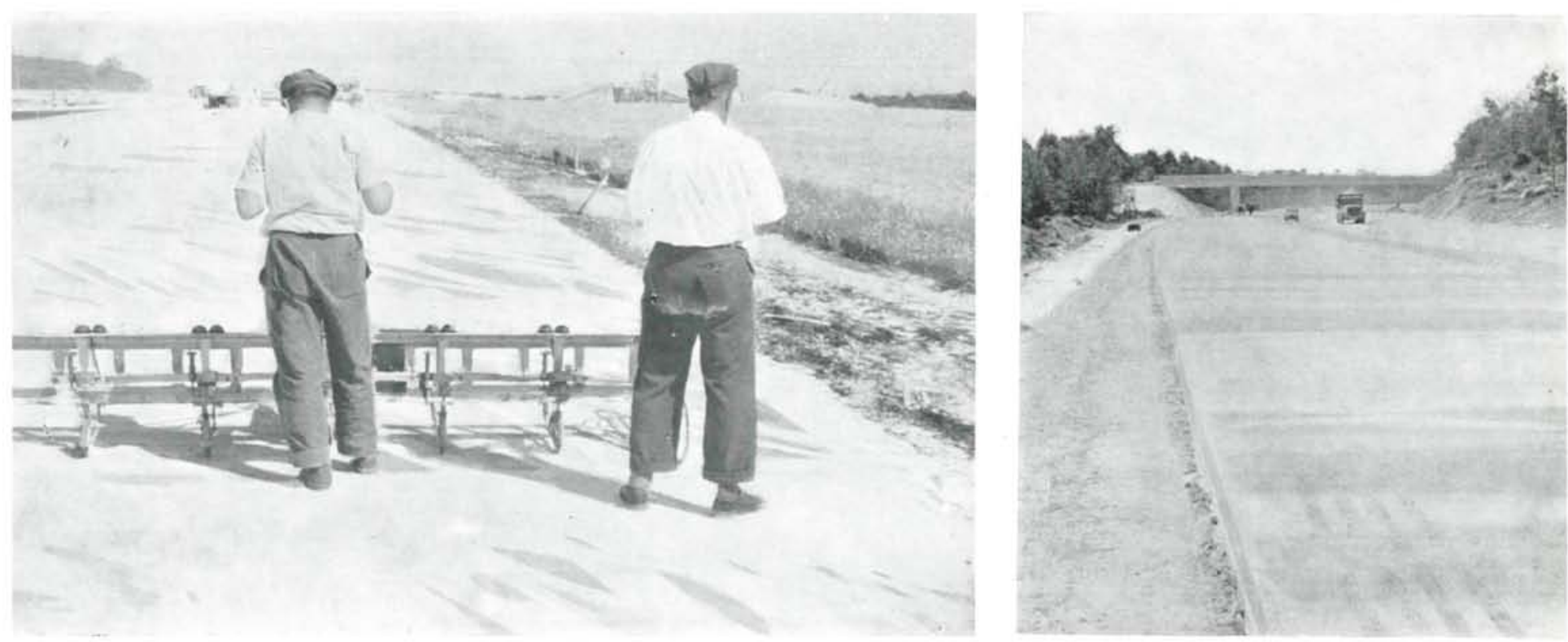

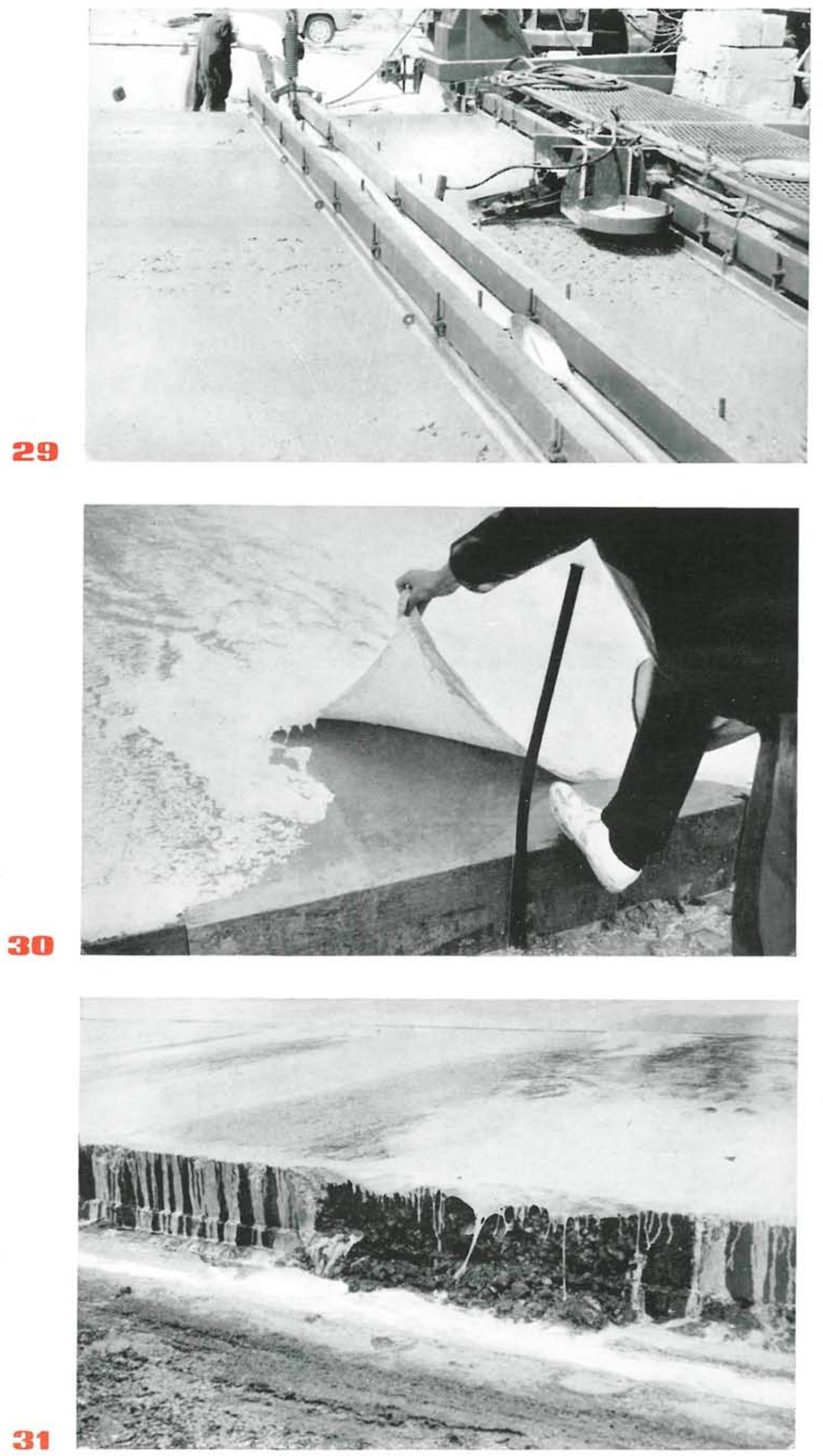

Para obviar el inconveniente, cabe hacer andar la máquina en vacío, hasta separarla dos metros del trozo último ejecutado, con lo que resulta un corte de esa amplitud que hay que ejecutar posteriormente a mano. Esta solución no es buena, por la inferior calidad que se obtiene en los trabajos manuales.

Otra solución consiste en calzar las orugas de la máquina con listones finos de madera, para levantarla un par de centímetros mientras rebasa la zona crítica. Pero, aun así, la transición entre el hormigón nuevo y el antiguo resulta siempre defectuosa y es prácticamente imposible evitar irregularidades, tanto en el espesor como en la capa superficial del pavimento.

\section{Tiempo Ilenvioso}

Cuando el tiempo es lluvioso no puede emplearse un producto ordinario de curado, pues sería arrastrado por el agua, y desaparecería a los pocos momentos. Se utiliza entonces un producto especial, mucho más filmógeno (y mucho más caro) que el ordinario, que forma una verdadera sábana protectora sobre la superficie del hormigón (fotografía 30). No obstante, por escasa que sea la lluvia, el hormigón recién ejecutado acusa la falta de encofrado permanente y los bordes de la losa comienzan a degradarse, desmoronándose progresivamente (fotografía 31). La degradación se inicia en el mismo momento en que la losa abandona el encofrado deslizante, por formación de fisuras paralelas al borde y próximas a él, que van progresando en amplitud hasta el completo hundimiento de las lajas separadas por ellas.

El resultado final es que hay que acudir a la defensa del hormigón fresco, encofrándolo con tablones que lo mantengan en su 


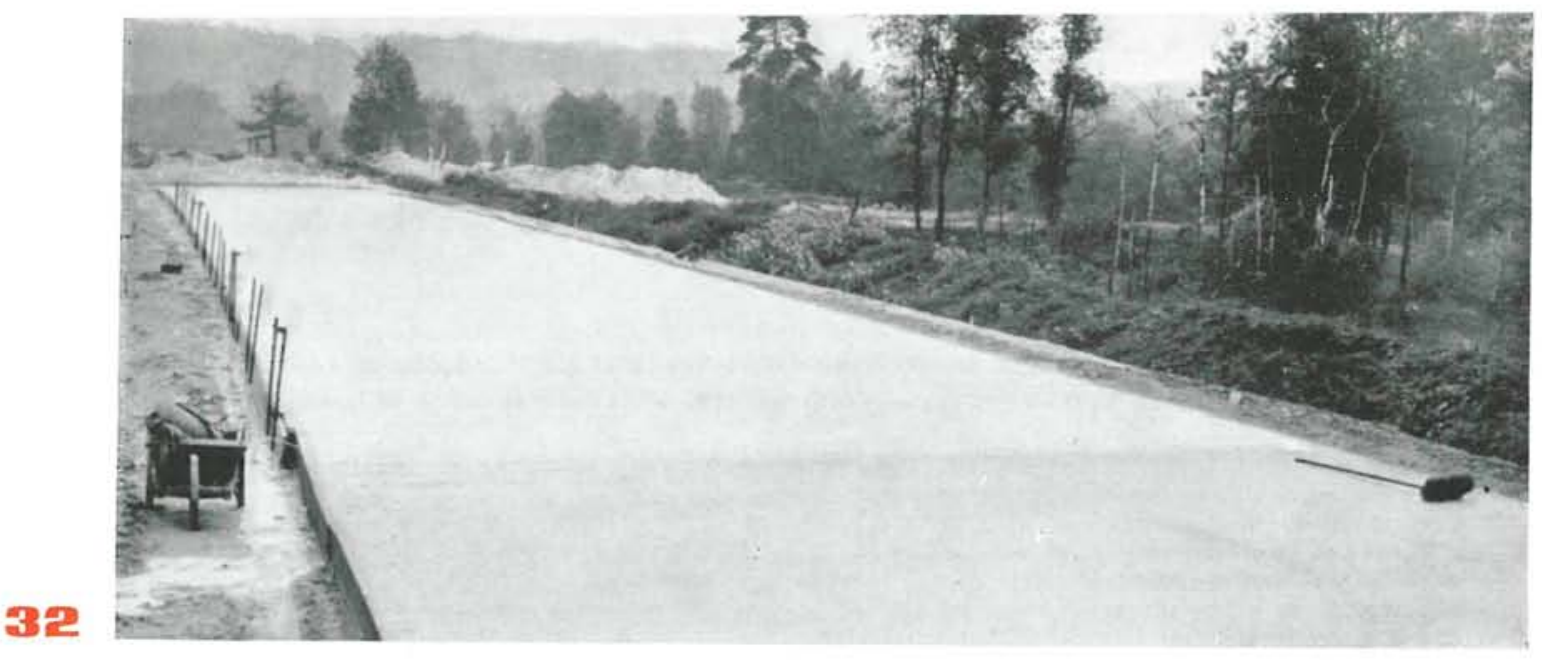

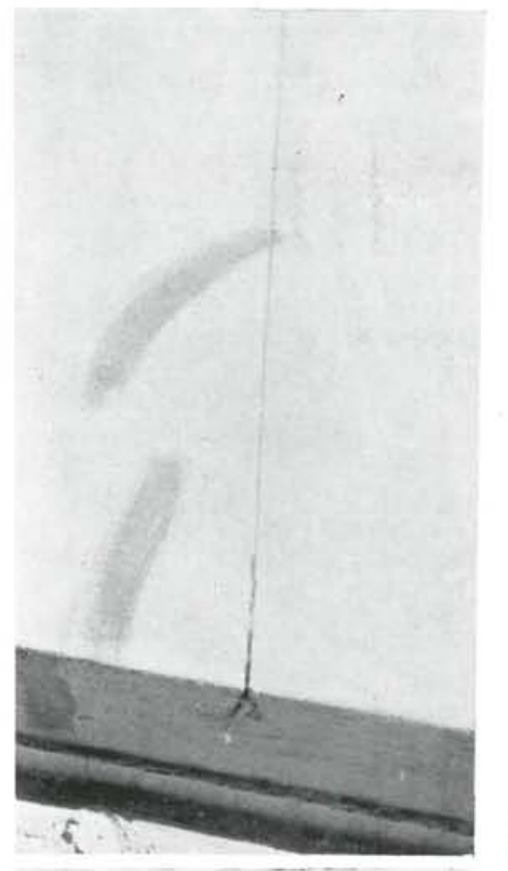

33

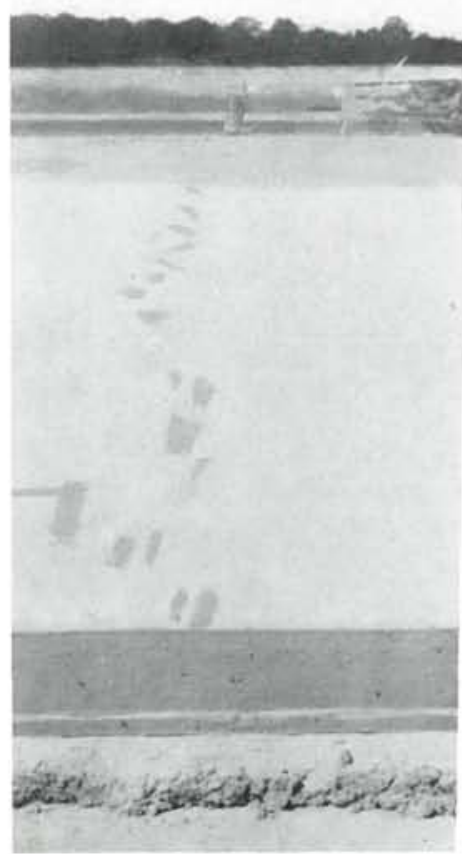

lugar y forma primitivos, como se muestra en la fotografía 32. Y la conclusión evidente es que no debe trabajarse en tiempo lluvioso con la máquina de encofrado deslizante.

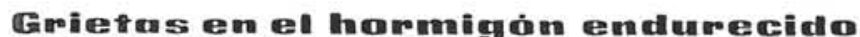

Este defecto tiene su origen en la disposición oblicua de las juntas. Por una parte, a las pocas semanas de su ejecución y antes de haber soportado ninguna carga, un cierto número de losas se fisuran por su esquina aguda, en la forma que aparece en la fotografía 33. Por otra parte, más o menos a la misma edad, algunas losas se fisuran a todo ancho, arrancando la grieta de una junta existente y siguiendo una dirección sensiblemente normal al eje del pavimento (fotografía 34). Parece como si la grieta quisiera enseñarle a la junta cuál es el trazado correcto que ésta debería haber seguido para no violentar al hormigón. Dicho de otro modo, parece como si el hormigón se negara a fisurarse de un modo distinto al perpendicular a su eje longitudinal, y ello con tal empeño que prefiere romper por otra sección aunque no esté debilitada.

\section{Comclusiomes}

1. La máquina de encofrado deslizante realiza un pavimento de excelente calidad, con mínimo empleo de mano de obra, con una organización general muy simple de los trabajos y con un elevado rendimiento.

2. Es imprescindible disponer de una central de hormigonado adecuada en capacidad y en calidad.

3. Sería deseable mejorar la visibilidad de los alambres de guiado, para eliminar una causa de posibles defectos en la ejecución.

4. Los trabajos sólo pueden llevarse a cabo si el tiempo no amenaza lluvia.

5. Parece dudosa la conveniencia de disponer juntas transversales oblicuas en un pavimento de hormigón.

6. El acabado superficial que proporciona la máquina de encofrado deslizante es bueno, pero inferior al obtenido con otros procedimientos de ejecución más tradicionales.

7. En resumen: el sistema está ideado para conseguir «mucha cantidad con buena calidad» antes que "mucha calidad con buena cantidad». Su empleo parece muy indicado en un país como Estados Unidos (carestía de mano de obra, máxima mecanización, gran número de autopistas, alto nivel económico), pero su adecuación a paises como el nuestro debe ser objeto de un estudio más detenido.

\section{Agr cu decimiemto}

$\mathrm{Me}$ es grato hacer constar mi reconocimiento al ingeniero G. Reverdy, director de la obra, y a cuantas personas colaboran con él, por las atenciones y facilidades que en todo momento me dispensaron durante mis visitas.

Fotss del autor 


 bètonmeuse di coffrouge glisscumt. Automoute Paris-Lyon}

A. García Meseguer, ingénieur des Ponts et Chaussées.

Cet article décrit l'exécution d'une chaussée de béton en masse à l'aide de la bétonneuse à coffrage glissant Gunter-Zimmermann, de fabrication nord-américaine. Cette bétonneuse qui est guidée automati. quement à l'aide de contacts électroniques, réalise, sans solution de continuité, les opérations suivantes: elle répartit le béton sur une largeur de $7,50 \mathrm{~m}$, le vibre, lui donne la forme voulue et l'épaisseur définitive dans son coffrage glissant, exécute une rainure longitudinale qui sert de joint, remplit cette rainu. re d'une bande en matière plastique, introduit une armature de renforcement du joint à la moitié de l'épaisseur de la dalle et nivelle la superficie finale.

Après avoir parlé du finissage superficiel, de la prise, de l'exécution par sciage des joints transversaux et des divers essais et vérifications, l'auteur analyse les possibilités et les limitations de ce procédé, pour arriver aux conclusions que l'on peut lire à la fin de l'article.

\section{Gonstruction of a Rigid pouvement with Slidiog Fomenwomk Echuipment. Pramiss Legon Motormagn}

A. García Meseguer, civil engineer.

This article describes the construction of a mass concrete pavement, carried out with the aid of a Gunter-Zimmermann sliding formwork, manufactured in the United States. This device guides itself automatically by means of an electronic control, and does the following set of operations simultaneously: it spreads the concrete over the whole width of the pavement $(7.5 \mathrm{~ms})$; vibrates it; shapes it and gives it the final thickness with the aid of the sliding formwork; it provides a longitudinal cut, which serves as a dilation joint; fills this joint with plastic material; places connecting reinforcements across the joint, half way down the depth of the pavement; and smoothes out the final surface.

The author refers to the final surface finish; discusses the sawing of the transversal joints, various tests and checks, and the possibilities and limitations of this constructional procedure. He finishes by ennumerating some general inferences on this method of road construction.

\section{Herstrellumg eimern streifen Decke mit eimen

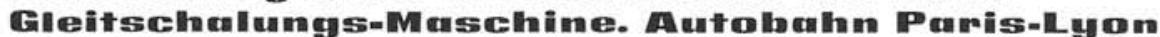

A. García Meseguer, Bauingenieur.

Es wird die Ausführung einer Decke aus Massenbeton mit der in Nordamerika hergestellten Gleitschalungs-Maschine Gunter-Zimmermann beschrieben. Diese Maschine, welche mittels elektronischer Kontakte automatisch geleitet wird, führt ohne Unterbrechung die folgenden Arbeiten aus:

Sie verteilt den Beton auf die ganze Breite $(7,50 \mathrm{~m})$, rüttelt ihn, verleiht ihm die endgültige Form und Dicke innerhalb seiner Gleitschalung, schneidet eine Längsspalte, welche als Fuge wirkt, füllt diese Spalte mit einem Kungststoffband, führt bis zur halben Dicke der Platte eine Verbindungs-Bewehrung ein und glättet die endgültige Oberfläche.

Nachdem der Verfasser sich auf die Oberflächen-Fertigung, Nachbehandlung, Ausführung des Schneidens der Querfugen und auf verschiedene Versuche und Prüfungen bezogen hat, analysiert er die Möglichkeiten und Beschränkungen dieses Vorganges und gelangt zu den Schlussfolgerungen, die am Ende des Textes verzeichnet sind. 